\title{
Development and Evolution of Hospital Medicine in Korea
}

\author{
Wonjeong Chae, BS 1,2, Eun-Cheol Park, PhD, MD2,3, Kang Young Lee, PhD, MD4, \\ Hyun-Jae Kang, PhD, MD5, Woo Yong Lee, PhD, MD ${ }^{6}$, Young Mo Kim, PhD, MD7, Sung-In Jang, PhD, MD2,3*
}

'Department of Public Health, College of Medicine, Yonsei University, Seoul, South Korea; ${ }^{2}$ Institute of Health Services Research, Yonsei University, Seoul, South Korea; ${ }^{3}$ Department of Preventive Medicine, College of Medicine, Yonsei University, Seoul, South Korea; ${ }^{4}$ Department of Surgery, College of Medicine, Yonsei University, Seoul, South Korea; ${ }^{5}$ Department of Internal Medicine, College of Medicine, Seoul National University, Seoul National University Hospital, Seoul, South Korea; ${ }^{6}$ Department of Surgery, School of Medicine, Sungkyunkwan University, Samsung Medical Center, Seoul, South Korea; 'Department of Otolaryngology-Head and Neck Surgery, College of Medicine, Inha University, Incheon, South Korea.

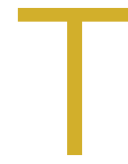

he healthcare system in South Korea (Korea) is evolving. Korea began developing a national health insurance system for the entire population in 1989, and implementation took 12 years. The healthcare insurance premium was set in 1989 when the Korean gross domestic product (GDP) per capita was less than $\$ 5,000$ USD. Since then, the incremental rise in healthcare insurance premiums, approximately $6 \%$ of the typical Korean income, has been relatively small considering the economic growth of Korea. ${ }^{1-3}$ The success and rapid adoption of national health insurance in Korea revealed unanticipated problems in three specific areas: low individual contributions relative to costs of care, low levels of reimbursement to providers, and incomplete coverage of medical services, which then require out-of-pocket payments (typically $20 \%$ of the inpatient care fee). ${ }^{4}$ Additionally, while little attention has been paid to quality and safety in the past, the nation has come to recognize the importance of these considerations, ${ }^{5}$ particularly with regard to patient expectations for and consumption of medical care and the consequent demand for better services from the medical community and government. ${ }^{6}$

Healthcare constitutes about $7.5 \%$ of Korea's GDP. In contrast, healthcare spending accounts for about $17.7 \%$ of US GDP and about $8.8 \%$ of the GDP of member nations of the Organisation for Economic Co-operation and Development (OECD) in aggregate. Additionally, Korea has a longer length of hospital stay ( 16.5 days vs 7.3 days for OECD countries) and fewer practicing physicians (1.1 per 1,000 persons vs 1.9 per 1,000 for OECD countries). Therefore, the average cumulative annual patient hospital days per physician is 2,394 days in Korea, three times higher than that in the OECD countries. ${ }^{7}$ Furthermore, the number of physicians providing hospital care in Korea has remained relatively low. ${ }^{8}$

Despite recent growth in the total number of practicing physicians, the number of hospital-based physicians remains insufficient to cover admitted patients. The pressure for hospital-based physicians to serve large numbers of patients

*Corresponding Author: Sung-In Jang, MD, PhD;

Email: JANGSI@yuhs.ac; Telephone: 82-2-2228-1862.

Published online first March 17, 2021.

Received: December 11, 2019; Revised: November 16, 2020;

Accepted: November 17, 2020

() 2021 Society of Hospital Medicine DOI 10.12788/jhm.3573 to generate sufficient revenue has deterred growth of more physicians focused on inpatient care. ${ }^{6}$ In order to operate the hospital, doctors must see as many patients as possible because physicians are reimbursed primarily by an inpatient care fee rather than by type or extent of care provided. Therefore, this low fee schedule makes it difficult to provide good quality inpatient care while simultaneously trying to increase accessibility. The costs of testing and treatment are reimbursed through a separate fee schedule.

\section{THE NEED FOR A HOSPITALIST SYSTEM IN KOREA}

The Korean government enacted two new policies regarding medical school graduates and residents that led to implementation of a hospitalist system. The first policy created a quota of medical residents to match the total number of medical school graduates. ${ }^{9}$ Before the new regulation, the number of medical resident positions exceeded the number of medical school graduates by $20 \%$, which led to a shortage of resident applicants in "unpopular" medical specialties or departments. These specialties (eg, general surgery, obstetrics and gynecology, urology) have a lower fee schedule, which leads to lower wages while having very high workloads. The decrease in the number of available medical resident positions results in greater workloads for physicians providing inpatient care. These changes, including the shortage of a resident workforce, led to a burgeoning hospital-based attending physician workforce to care for hospitalized patients.

The other policy, created in December 2015 and known as the Act on the Improvement of Training Conditions and Status of Medical Residents, was enacted to improve working conditions for residents by limiting their working hours to 80 or fewer per week. ${ }^{10}$ These work-hour restrictions made it nearly impossible to provide 24-hour inpatient care depending solely on residents..$^{10-12}$ This policy increased the need for hospitalists in Korea, similar to that of the US Accreditation Council for Graduate Medical Education in 2003, which limited resident work hours. Because of these changes, the hospitalist model was introduced to manage the growing volume of inpatients at teaching hospitals. ${ }^{13}$

The institutional implementation of the Korean hospitalist system was catalyzed by the need to solve current problems such as patient safety, healthcare quality, and residents' well-being. ${ }^{8,14}$ Therefore, the hospitalist system was designed 
TABLE. Pilot Studies of Korean Hospitalist Implementation

\begin{tabular}{lll}
\hline Dates & Main funding source & Outcomes \\
\hline $\begin{array}{l}\text { September } 2015 \text { to } \\
\text { August } 2016\end{array}$ & Private organizations $^{\mathrm{a}}$ & $\begin{array}{l}\text { Increased accessibility } \\
\text { Increased patient satiffaction with care } \\
\text { Increased patient satisfaction with doctors }\end{array}$ \\
\hline $\begin{array}{l}\text { September 2016 to } \\
\text { December 2020 }\end{array}$ & Government & $\begin{array}{l}\text { Increased accessibility } \\
\text { Increased patient satisfaction with care } \\
\text { Increased consulting and face-to-face services } \\
\text { Positive work outcomes with hospitalists among medical staff (nurses, residents, other doctors) }\end{array}$ \\
\hline $\begin{array}{l}\text { a These organizations included the Korean Association of Internal Medicine, Korean Surgical Society, Korean Medical Association, Korean Hospital Association, and Korean Academy of Medical } \\
\text { Sciences. }\end{array}$ \\
${ }^{5}$ Evaluation has been completed; however, the new system is in the government's administrative process. \\
\hline
\end{tabular}

and implemented to meet the needs of patients, medical professionals, and hospitals. 6,8,14 Furthermore, under the universal health insurance system in Korea, institutional implementation also meant creating a new set of fee schedules for hospitalists. The Korean hospitalist system reflects the nuances and challenges faced by the Korean healthcare system. ${ }^{5}$

\section{DESIGN, IMPLEMENTATION, AND EVALUATION}

A council was formed to implement a hospitalist model suitable for Korea. The council was composed of five groups: the Korean Association of Internal Medicine, Korean Surgical Society, Korean Medical Association, Korean Hospital Association, and Korean Academy of Medical Sciences. The Korean Association of Internal Medicine and the Korean Surgical Society were involved in creating a new medical discipline because their members provided a disproportionate amount of inpatient care and were most often responsible for hospital patient safety and quality care. Along with the support of the council, the Ministry of Health and Welfare began to realize the high demand on inpatient care and requested an official proposal to broaden the hospitalist model, with two conditions. First, the government requested a unified proposal from the medical community that reflected the collective voices of individual stakeholders, with an expectation that the new system would focus on patient safety and healthcare quality across all specialties. Second, the proposal had to be detailed and include a specific fee schedule for hospitalist services.

Before implementing a national hospitalist system, we conducted a pilot study supported by funding from the council. This first study, the Korean Hospitalist System Operation and Evaluation Research (September 2015 to August 2016) ${ }^{14}$, was designed to (a) determine hospitalist needs (eg, rotation schedule, salary, working conditions) for this new profession, (b) determine the necessary number of hospitalists and appropriate fee schedules to cover salary and benefits, and (c) provide Korean hospitalist models with operational methods to facilitate implementation at individual institutions. The council and research team selected four hospitals for the privately funded pilot study (Table). These hospitals already had an inpatient care system managed by specialists prior to the pilot study, so major changes in patient care and hospital operations were not required.

The pilot study demonstrated improvements in patient satisfaction, medical service quality, and patient safety. ${ }^{8,14,15}$ As a result, fees billed from hospitalist services were now covered by national health insurance; previously, they were not covered by any inpatient care fee or bundled service fee. The next study (phase 2) was then conducted to evaluate the national implementation of the hospitalist system and its outcomes. The first phase defined criteria for monitoring and evaluating the institutionalized hospitalist system in Korea. The second phase, initiated in September 2016, evaluated how the implemented system could be expanded nationwide. The government was actively involved in the study; 31 of 344 (9\%) general hospitals were selected and able to apply the hospitalist fee schedule for care of patients who were admitted to the hospitalist ward.

To investigate the effect of the hospitalist system, we measured the satisfaction of patients and medical providers (eg, specialists, residents, and nurses). The outcomes were number of doctors' calls to hospitalists and to other specialties, duration of time required to address medical problems, number of contacts with the hospitalist (residents or other physicians in the control group), and time spent with hospitalized patients. In addition, we analyzed claims costs and the operating costs for implementing the system within each hospital (Table).

The new set of fee schedules was created specifically for hospitalist care services so hospitals could now claim separate inpatient care fees and hospitalist fees. The standard hospitalist fee schedule is applied only to patients who are on hospitalist-led wards. The fee schedule has two criteria: The hospitalist ward must have 50 beds which are assigned to hospitalists only, and each hospitalist ward has a team of five hospitalists. A maximum of 25 patients could be assigned to an individual hospitalist. However, fees can be adjusted based on individual hospital operation and management after government approval.

Under the national insurance system, the fee schedule is essential to obtain reimbursement for provided services. As a new medical profession, it is important to have the institutional implementation of the hospitalist system. In contrast to those in the United States, inpatients in Korea pay inpatient care fees only, which are charged per day. Therefore, reducing 
the length of stay without increasing patient volume does not financially benefit the hospital.

\section{DEFINITION OF A KOREAN HOSPITALIST AND SCOPE OF PRACTICE}

The definition of a Korean hospitalist was carefully developed, and a reimbursement system for hospitalists was created within the Korean healthcare system. All hospitalists are medical specialists who have completed advanced education and clinical training in their specialty area (internal medicine or surgery). Creating a definition of a hospitalist and a standard fee schedule was necessary for national incorporation of this new approach. The model must also be accepted by related parties, including healthcare professionals such as hospital executives, nonhospitalist doctors, and nurses. Therefore, the system has a minimum of two requirements to operate at the hospital level, and the remaining factors can be modified by individual hospitals to protect the new discipline within the healthcare system. First, hospitalist services are provided only to hospitalist patients. To establish the new system, limiting the patient range to a specific group was necessary to prevent abuse of human-based resources within the hospital. Second, hospitalists must be stationed near the hospitalist ward to enhance accessibility, patient safety, and healthcare quality. In other words, a hospitalist provides services to hospitalized patients who paid the hospitalist fee, and the hospitalist does not provide care beyond the hospitalist ward (eg, they cannot provide outpatient consultation or provide care on other wards).

\section{INPATIENT CARE REIMBURSEMENT BEFORE AND AFTER IMPLEMENTATION}

Korean national health insurance is the universal health insurance under a single insurer (ie, the government). Therefore, all Korean citizens have national health insurance. Individuals can choose to have additional health insurance (private insurance) if they wish to pay an out-of-pocket fee with their additional private insurance. In Korea, the inpatient care fee includes all fees to provide care for the patient during hospital stays, such as the physician fee, facility fee, and consultation fee. The inpatient care fee schedule is charged per day including all the inpatient care composition. The claim and reimbursement system is different in Korea in that the hospital as a whole submits the claim for reimbursement. There is no separate claim from physicians, lab technicians, or facilities. Doctors provide care to patients and are then paid for the services in terms of salaries. Since the original inpatient care fee schedule was low and insufficient, it was difficult to provide high-quality care. Also, resources for spending on inpatient care management was limited. So a new system to improve inpatient care was needed. Implementing the hospitalist system in Korea led to the creation of a new fee schedule specifically for hospitalists so that hospitals could claim hospitalist fees on top of inpatient care fees when the patient was cared for by the hospitalist. The additional fees in the hospitalist fee schedule allow safe and high-quality care to be provided for patients during hospital stays.

\section{KOREAN HOSPITAL MEDICINE TODAY}

The Korean hospitalist system has been implemented for 3 years with the government's active involvement, with approximately 250 specialists working as hospitalists as of August 2020. Importantly, Korean hospitalists are not limited to internal medicine specialists; in fact, several different specialties practice as hospitalists, including surgeons and other medical specialists, who account for $20 \%$ and $30 \%$ of the hospitalist workforce, respectively. Since the system's implementation, all inpatient care and management is now transferred to specialists from residents in hospitalist wards. This change has increased patient safety and care quality. At the beginning of the pilot study, the concept of a "hospitalist" was new in Korea and the public did not know who a hospitalist was nor what a hospitalist did. However, after 3 years, patients now seek hospitalist care.

\section{CONCLUSION}

National implementation of the hospitalist model represents a key paradigm shift in the Korean healthcare system. The Korean hospitalist system is the result of the hospitals', doctors', and patients' desire for higher-quality care. We expect to see growth of hospitalists in Korea and provision of better, safer, and more efficient inpatient care across specialties, payers, and government. Since we are at the early stage of the system, further efforts to support implementation are required. We hope our implementation process of a new medical system could serve as a model for other countries who are seeking to adopt hospitalist systems within their current healthcare paradigms.

\section{Acknowledgments}

The authors thank the medical professionals, government officers, and other professionals who put great effort into the implementation of the Korean Hospitalist System.

Disclosures: Dr Jang is the recipient of a grant from Yonsei University College of Medicine. The other authors have nothing to disclose.

Funding: This study was supported by a faculty research grant from Yonsei University College of Medicine (6-2017-0157 and 6-2018-0174).

\section{References}

1. Kwon S. Thirty years of national health insurance in South Korea: lessons for achieving universal health care coverage. Health Policy Plan. 2009;24(1): 63-71. https://doi.org/10.1093/heapol/czn037

2. Song YJ. The South Korean health care system. JMAJ. 2009;52(3):206-209.

3. Park YH, Park E-C. Healthcare policy. In: Preventive Medicine and Public Health. Vol 3.Gyechuk; 2017:821-833.

4. Park E-C, Lee TJ, Jun BY, Jung SH, Jeong HS. Health security. In: Preventive Medicine and Public Health. Vol 3. Gyechuk; 2017:888-897.

5. Jang S-I, Jang S-y, Park E-C. Trends of US hospitalist and suggestions for introduction of Korean hospitalist. Korean J Med. 2015;89(1):1-5. http://doi. org/10.3904/kjm.2015.89.1.1

6. Jang S-I. Korean hospitalist system implementation and development strategies based on pilot studies. J Korean Med Assoc. 2019;62(11):558-563. http:// doi.org/10.5124/jkma.2019.62.11.558

7. OECD. Health at a Glance 2017: OECD indicators. OECD iLibrary. 2017. Accessed September 27, 2019. https://doi.org/10.1787/health glance-2017-en

8. Jang S-I, Park E-C, Nam JM, et al. A study on the implementation and the evaluation of Korean Hospitalist System to improve the quality of hospitalization (Phase 2). Institute of Health Services Research, Yonsei University; 2018.

9. Koh DY. Political strategies to enhance medical residents. Health Policy. Vol 
37. Seoul National University Hospital; 2014.

10. Act on the Improvement of Training Conditions and Status of Medical Residents. Vol No. 16260: Ministry of Health and Welfare; 2015.

11. Eom JS. Operating the hospitalist system. J Korean Med Assoc 2016;59(5):342-344. http://doi.org/10.5124/jkma.2016.59.5.342

12. Kim S-S. Working conditions of interns/residents and patient safety: Painful training might not be authentic. J Korean Med Assoc. 2016;59(2):82-84 http://dx.doi.org/10.5124/jkma.2016.59.2.82

13. Oshimura J, Sperring J, Bauer BD, Rauch DA. Inpatient staffing within pedi- atric residency programs: work hour restrictions and the evolving role of the pediatric hospitalist. J Hosp Med. 2012;7(4):299-303. https://doi.org/10.1002/ jhm.952

14. Park E-C, Lee SG, Kim T-H, et al. A study on the implementation and the evaluation of Korean Hospitalist System to improve the quality of hospitalization (Phase 1). Institute of Health Services Research, Yonsei University; 2016.

15. Jang S-I, Jung E-J, Park SK, Chae W, Kim Y-K. A study on the feasibility of the Korean hospitalist system and cost estimation. Ministry of Health and Welfare, Institute of Health Service Research Yonsei University; 2019. 